\title{
PRODUKTIVITAS DAN BIAYA PENGANGKUTAN BIBIT PADA MEDAN SULIT DENGAN SISTEM KABEL LAYANG
}

\section{(Productivity and Cost of Seedling Transportation on Heavy Terrain Using Skyline Cable System)}

\author{
Oleh/By : \\ Wesman Endom, Yayan Sugilar \& Silvanus Suprapto
}

\begin{abstract}
This study examined performances of the improved equipment, namely Semanggi-I, in conveying seedling around the heavy terrain. Results indicated that Semanggi-I performed better than the first prototype. Semanggi-I could convey approximately 5,000-6,000 seedlings. hm/ hour wich is twice as much the productivity of prototype-I. Although the fix and operating cost of Semanggi-I is somewhat higher than the first prototype, the average transportation cost of SemanggiI is only $\mathrm{R} p 7 /$ seedling which is about half of the cost when using prototype-I.
\end{abstract}

Key words: Forest and land rehabilitation, field constraints, seedling transportation, skyline system.

\begin{abstract}
ABSTRAK
Indonesia saat ini terus giat melakukan upaya rehabilitasi hutan dan lahan. Dalam pelaksanaannya kegiatan ini mengalami berbagai kesulitan lapangan, terutama medan yang curam. Untuk mengangkut bibit di area seperti itu perlu dipertimbangkan solusi untuk cara pemecahannya. Hasil studi pertama dengan menggunakan rekayasa alat Prototipe-I, telah memberikan hasil cukup nyata.

Pada pengujian untuk mengangkut bibit pada medan berat ini, diteliti rekayasa alat angkut bibit yang telah ada perbaikannya dengan sebutan Semanggi-I. Hasilnya memperlihatkan bahwa kinerja Semanggi-I lebih baik dari pada Prototipe-I. Semanggi-I dapat mengangkut sekitar 5.000-6.000 bibit.hm/jam yang adalah dua kali produktivitas Prototipe-I. Meskipun biaya tetap dan biaya operasi Semanggi-I lebih besar dibanding Prototipe-I rata-rata biaya pengangkutan bibit Semanggi-I adalah hanya Rp 7 per bibit yang kurang lebih setengahnya daripada biaya pengangkutan bibit dengan Prototipe-I.
\end{abstract}

Kata kunci: Gerhan, kendala lapangan, angkutan bibit, sistem kabel layang.

\section{PENDAHULUAN}

Pembangunan Hutan Tanaman Industri (HTI) maupun hutan rakyat kini memiliki peran penting dalam upaya memenuhi kebutuhan kayu nasional. Hasil-hasil penelitian memperlihatkan bahwa produksi kayu hutan tanaman dapat mencapai lima kalinya dibanding hutan alam. Oleh karena itu pembangunan HTI merupakan langkah pilihan yang positif dan prospektif (Harahap, 1989). 
Untuk membangun hutan tanaman, banyak risiko dan kendala yang dihadapi sejak persiapan/pembukaan lahan, praktik silvikultur (pemilihan jenis, persemaian, penanaman, pemeliharaan), ekonomi finansial (penyediaan dana) dan pada manajerialnya. Khusus mengenai bibit, di dalamnya terdapat masalah bagaimana cara pengangkutannya yang aman, mudah dilakukan, ringan, mutu bibit terjaga, alatnya cukup tahan lama serta mudah dibangun oleh masyarakat dengan harga murah (Djapilus, 1988). Hal ini penting mengingat lokasi yang akan direhabilitasi umumnya berada di daerah sulit, sehingga perlu segera diantisipasi untuk menemukan solusinya.

Untuk pengiriman bibit pada medan sulit dan bentangan cukup jauh ditambah dengan tanah yang licin akibat hujan, maka penggunaan cara pikul dinilai tidak efektif dan efisien, karena sangat berisiko baik bagi keselamatan tenaga kerja maupun bibit yang diangkutnya. Oleh karena itu, sering disinyalir mengapa banyak orang kemudian melakukan tindakan tak terpuji pada kegiatan proyek penghijauan yakni memikul bibit dengan cara membuang tanahnya dari polibeg (polybag). Dengan cara itu ratusan hingga ribuan bibit sampai di lokasi tanam mati akibat terganggu sistem perakarannya. Sinyalemen ini sebagaimana dikatakan Joyoadikusumo (2004) diakibatkan kondisi biofisik lokasi Gerakan Nasional Rehabilitasi Hutan dan Lahan (GN-RHL) bervariasi. Karena tiap daerah berbeda kondisinya, maka perlakuan bagi setiap lokasi berbeda pula. Umumnya karena kurang ketat dalam pengawasan, maka dengan sistem plances yang relatif berat, bibit akan dicabuti buruh dari polibeg sebelum sampai di lokasi tanam di pegunungan. Akibatnya tanaman gagal. Demikian juga dengan penanaman bibit yang diangkut dengan cara manual.

Sebagai antisipasi masalah itu, pada tahun 2004 dibangun sebuah prototipe alat pengangkut bibit sistem kabel layang dengan menggunakan mesin sepeda motor sebagai tenaga penggeraknya. Sesuai dengan sifatnya, pergerakan kabel muatan hanya dapat berjalan searah. Pada tahun 2005, sejenis alat yang sama dibangun dengan tenaga penggerak menggunakan mesin diesel 7 PK (tenaga kuda). Berdasarkan hasil kajian itu, prototipe alat kedua dapat menjadi pilihan, karena selain kinerjanya lebih baik dibanding prototipe pertama juga pergerakan kabel dapat dijalankan dua arah maju atau mundur. Prototipe kedua ini dilengkapi dengan dua buah drum. Drum pertama untuk mengangkat atau menurunkan muatan bibit, sedang drum yang kedua berfungsi untuk menarik atau memundurkan keranjang muatan bibit. Selain itu, alat ini dirancang juga agar dapat berjalan sendiri. Alat ini diberi nama Semanggi-I.

Dengan adanya alat Semanggi-I diharapkan pengiriman bibit pada medan sulit dapat diatasi dan oleh karenanya akan dihasilkan percepatan penanaman dengan kualitas bibit yang sehat dan persen tumbuh yang tinggi.

\section{BAHAN DAN METODE}

\section{A. Lokasi}

Uji coba kegiatan penelitian tahun 2004 dilakukan di kawasan hutan Carita, Propinsi Banten, dengan bentangan kabel sejauh 180 m, melewati lereng terjal dan sungai selebar $15 \mathrm{~m}$. Untuk penelitian tahun 2005, uji coba dilakukan di RPH Ciguha, Sukabumi dengan bentangan kabel sejauh $320 \mathrm{~m}$ melewati lembah, perbukitan serta sawah dan sungai kecil. 


\section{B. Bahan dan Alat}

\section{Bahan}

Bahan yang dipergunakan adalah berupa bibit tanaman serta bahan bakar (solar dan bensin). Sedangkan alat yang dipakai ada dua macam yaitu prototipe rekayasa awal dengan penggerak mesin sepada motor dan prototipe Semanggi-I dengan penggerak mesin diesel 7 PK. Alat lainnya yang dipakai adalah stop watch, keranjang bibit, katrol, kabel, kito dan klem pengunci.

\section{Alat}

a. Prototipe awal

Prototipe ini alat dibangun untuk menarik keranjang berisi bibit dengan sistem kabel layang kabel melalui tanpa ujung (endless). Prototipe sejenis yarder mini ini dibangun dengan memodifikasi mesin motor Honda $70 \mathrm{cc}$ sebagai penggerak putarannya. Untuk pendingin mesin, dipasang kipas mobil berukuran sedang yang ditempatkan di depan mesin tersebut.

Pada saat dioperasikan, roda depan dan belakang diangkat kemudian ditopang dengan kaki-kaki besi siku yang dapat dilipat. Agar posisi mesin stabil dan aman, di belakang mesin dipasang kabel pengaman (guy line) yang diikatkan di pohon. Kelemahan pada model ini gerakan kabel tidak dapat dibuat dalam sistem gerakan maju mundur, serta mesin cepat panas karena putaran kipas agak lemah sehingga mengakibatkan konsumsi bahan bakar cukup boros.

\section{b. Prototipe Semanggi-I}

Pada prototipe ini, mesin yang digunakan untuk penggeraknya ialah diesel berkekuatan 7 PK. Pada mesin ini terdapat 3 (tiga) buah gigi penggerak yaitu untuk menggerakan roda maju mundur, menaikan dan menurunkan keranjang serta menarik atau mengulur keranjang Ketiga gigi penggerak tersebut dapat dijalankan sendiri-sendiri atau secara bersamaan sekaligus, sehingga cukup efektif dalam mengatasi kendala lapangan.

Prototipe model Semanggi-I komponen utamanya terdiri dari mesin diesel, Gear box, gigi transmisi, drum pengangkat (lifting drum), drum penarik (pulling drum), setir dan dilengkapi dengan dua buah rem (brake).

Pada saat alat ini dioperasikan, roda belakang diangkat kemudian ditopang dengan kaki besi kotak yang dapat dicopot. Untuk kestabilan dan keamanan, di bagian depan mesin dipasang kabel pengaman (guy line) yang diikatkan di pohon.

Kedua model prototipe alat angkut bibit versi pertama yang menggunakan penggerak mesin sepeda motor dan model Semanggi-I yang menggunakan mesin diesel disajikan pada Gambar 1 dan 2 .

\section{c. Praktek pengangkutan bibit}

Proses dan tahapan kerja pada operasi pengangkutan bibit sistem kabel layang dengan menggunakan keranjang sebagai wadah bibit dilakukan sebagai berikut.

1. Pilih lokasi yang relatif datar dan lebar untuk menempatkan posisi alat agar aman, nyaman, efektif dan efisien.

2. Tetapkan jalur dan lintasan kabel dan bersihkan selebar 3 meter. 


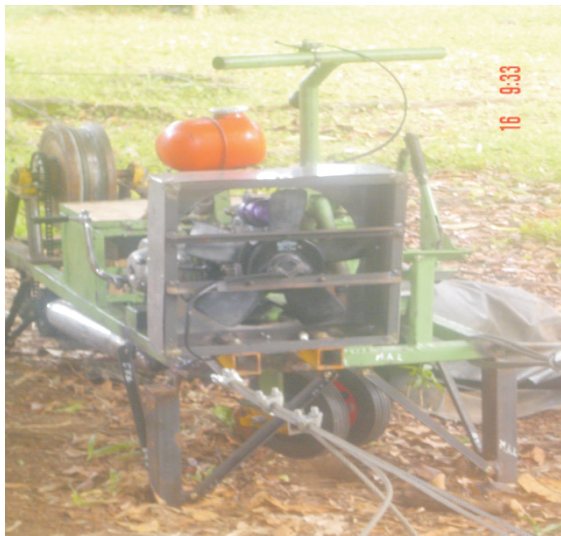

1a

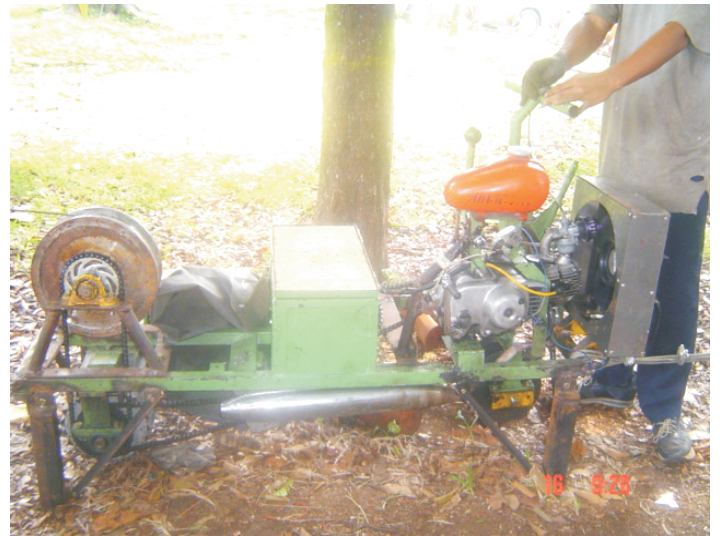

$1 \mathrm{~b}$

Gambar1. Prototipe alat angkut bibit kabel layang. Tampak depan (1a) dan tampak samping (1b)

Figure 1. The prototype of seedling transportation of skyline system. The appearance of front view (1a) and the appearance of side view (1b)

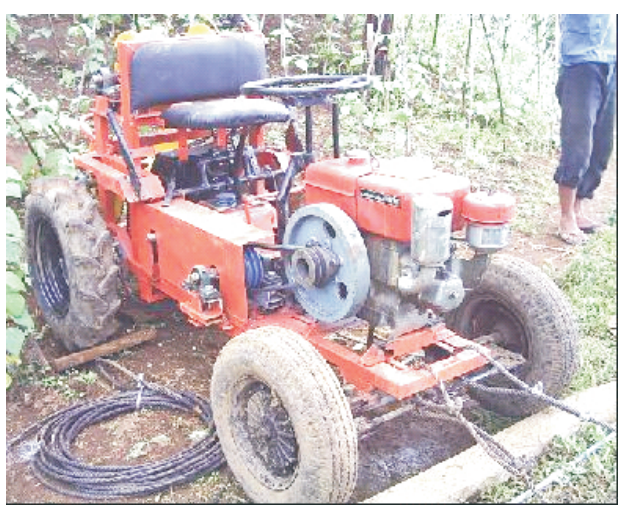

$2 a$

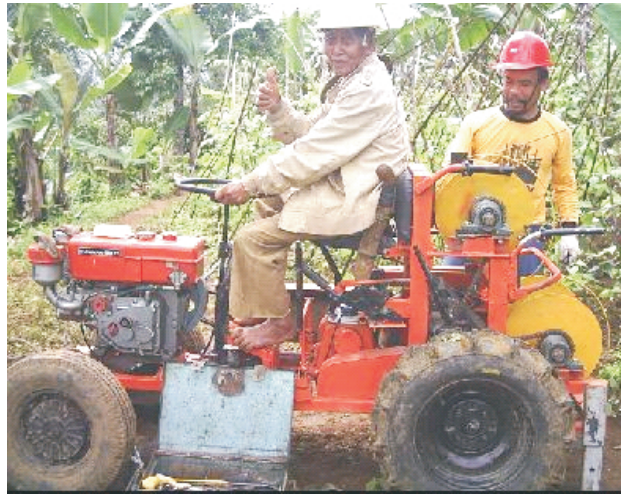

$2 b$

Gambar 2. Prototipe alat angkutan bibit model Semanggi-I. Tampak depan (2a) dan Tampak samping (2b)

Figure 2. The prototype for seedling transportation of Semanggi-I. The appearance offront view (1a). The appearance of side view (1b)

3. Pilih pohon untuk tempat pemasangan kabel berikut kabel pengaman.

4. Pasang katrol, kabel utama dan kabel penarik.

5. Pasang kereta penarik keranjang dan siapkan 10-15 keranjang bibit.

6. Hidupkan mesin dan lakukan uji coba penarikan keranjang.

7. Siapkan petugas dan buat simbul komando proses pengangkutan bibit.

8. Isi tiap keranjang dengan bibit yang akan ditanam dan hitung jumlahnya.

9. Catat waktu pada setiap pengangkutan bibit dan kelemahan selama proses. 


\section{Pengumpulan Data}

Data yang dikumpulkan meliputi jenis dan ukuran bibit (diameter dan tinggi bibit), jarak angkut (meter), waktu pemuatan (menit), pembongkaran (menit) dan penarikan (menit) serta mengamati kelemahan kinerja alat.

\section{Pengolahan Data}

1. Menghitung jumlah bibit yang terangkut pada keranjang berukuran $60 \times 90 \mathrm{~cm}$.

2. Menghitung produktivitas kerja pengriman bibit.

$$
\mathrm{PK}=\frac{\mathrm{N} \times \mathrm{J}}{\mathrm{W}}
$$

dimana $\mathrm{PK}=$ Produktivitas angkutan bibit ( bibit $. \mathrm{hm} / \mathrm{jam}$ ); $\mathrm{N}=$ jumlah bibit (bibit); J = Jarak (m) dan W = Waktu kerja efektif (menit)

3. Analisis biaya

a. Baya penyusutan (Bp)

$$
\mathrm{Bp}=\frac{\mathrm{M}-\mathrm{R}}{\mathrm{N} \mathrm{xt}}
$$

dimana $\mathrm{Bp}=$ penyusutan $(\mathrm{Rp} / \mathrm{jam}) ; \mathrm{M}=$ investasi alat $(\mathrm{Rp}) ; \mathrm{R}=$ nilai alat bekas $(10 \%$ dari harga baru); $\mathrm{N}=$ umur pakai alat (tahun) dan $\mathrm{t}=$ waktu kerja alat (jam/tahun)

b. Bunga modal (Bm)

$$
\mathrm{Bm}=\frac{\{(\mathrm{M}-\mathrm{R})(\mathrm{N}+1)+\mathrm{R}\} \times 0,0 \mathrm{p}}{2}
$$

dimana $B=$ bunga modal $(\mathrm{Rp} / \mathrm{jam}) ; \mathrm{p}=$ suku bunga per tahun $(\%$ per tahun $)$, dan $\mathrm{t}=$ waktu kerja alat per tahun

c. Biaya perawatan (Bpr) (FAO, 1974)

$$
\mathrm{BP}=\frac{\text { Harga alat }(\mathrm{Rp}) \times 0,1}{1000 \mathrm{jam}}
$$

d. Biaya bahan bakar (Bb)

$$
\mathrm{Bb}=\text { Penggunaan (liter/jam) } \mathrm{x} \text { harga per liter }(\mathrm{Rp} / \mathrm{lt})
$$

e. Biaya oli dan pelumas (Bo) (FAO, 1974)

$$
\mathrm{Bo}(\mathrm{Rp} / \mathrm{jam})=\frac{\text { Harga alat }(\mathrm{Rp}) \times 0,005}{1000 \mathrm{jam}}
$$


Gaji (Rp/bulan)
(Bop)
(20 harix 8jam/hari)/bulan.

g. Biaya tenaga pembantu $(\mathrm{Rp} / \mathrm{jam})=\frac{\mathrm{Rp} 25.000 / \text { hari }}{\text { (Btp) }}$
8 jam $/$ hari

h. $\operatorname{Pajak}(\mathrm{Pj})=\frac{\mathrm{H} \times 0,6 \times 2 \%}{1000 \mathrm{jam}}$

i. Asuransi(As) $=\frac{\mathrm{Hx} 0,6 \times 3 \%}{1000 \mathrm{jam}}$

j. Biaya operasi pengiriman bibit (Bpb)

$\mathrm{Bpb}=\frac{\mathrm{Bp}+\mathrm{Bm}+\mathrm{Brm}+\mathrm{Bbm}+\mathrm{Bo}+\mathrm{Bop}+\mathrm{Btp}+\mathrm{Pj}+\mathrm{As}}{\mathrm{PK}}$

di mana $\mathrm{Bpb}=$ biaya pengiriman bibit $\left(\mathrm{Rp} / \mathrm{m}^{3}\right) ; \mathrm{Bpm}=$ biaya penyusutan alat muat bongkar (Rp/jam); Bm = biaya modal alat $(\mathrm{Rp} / \mathrm{jam}) ; \mathrm{Brm}=$ biaya perawatan alat (Rp/jam); Bbm= biaya bahan bakar (solar) (Rp/jam); Bo = biaya oli (Rp/jam); Bop $=$ biaya operator $(\mathrm{Rp} / \mathrm{jam}) ; \mathrm{Btp}=$ biaya tenaga pembantu $(\mathrm{Rp} / \mathrm{jam}) ; \mathrm{Pj}=$ pajak (Rp/jam); As = asuransi (Rp/jam) dan PK = produktivitas kerja (bibit/jam).

\section{HASIL DAN PEMBAHASAN}

Dari uji coba ini diketahui bahwa pengangkutan bibit dengan sistem kabel layang menggunakan prototipe awal maupun pada model Semanggi-I sama halnya untuk pengeluaran kayu. Untuk pemasangan jaringan kabel di daerah yang sulit diperlukan waktu 13 hari, tergantung jarak bentang, tingkat kesulitan lapangan, kesediaan tenaga kerja dan cuaca.

\section{A. Jumlah Bibit dalam Keranjang}

Bibit yang dipakai pada uji coba di Carita adalah hasil dari persemaian sendiri di Bogor yang terdiri dari jenis khaya (Swietenia macrophylla), rasamala (Altingia excelsa) dan damar (Agathis alba). Bibit-bibit tersebut merupakan anakan alam yang kemudian dipindahkan sebagai anakan dalam polibeg berukuran $8 \times 10 \mathrm{~cm}$. Bibit yang diuji coba seluruhnya sudah ada dalam keranjang.

Di lapangan dengan kondisi becek, basah dan licin akibat hampir setiap hari terjadi hujan, proses pemasangan kabel utama dan kabel endless yang harus melewati naik turun lereng penuh dengan semak belukar dan melewati sungai, sehingga merupakan kendala yang sangat berat. Hasil wawancara dengan para pekerja diperoleh keterangan bahwa untuk menempuh jarak $180 \mathrm{~m}$ dengan tingkat kesulitan tinggi, sedikitnya diperlukan waktu antara 
15 - 30 menit. Pengangkutan bibit dengan cara dipikul memerlukan waktu hampir satu jam, dengan kemampuan membawa bibit maksimum 100 polibeg ukuran diameter $8 \mathrm{~cm} /$ orang. Oleh karena itu cara manual di daerah seperti ini dinilai tidak efektif.

Pada uji coba yang dilakukan di Nyalindung, bibit diperoleh dari persemaian di lokasi setempat dari jenis mangium (Acacia mangium). Tinggi bibit bervariasi antara 40-90 cm yang ditanam pada polibag berukuran 8-10 cm. Dengan ukuran keranjang 60 x $90 \mathrm{~cm}$, setiap keranjang dapat diisi bibit antara 90-136 bibit. Dengan sejumlah bibit itu berat keranjang yang berisi tanaman antara 40-65 kg, tergantung ukuran tanaman. Bila berat keranjang kosong \pm 5 $\mathrm{kg}$, dan setiap polibeg yang terisi tanah berikut tanamannya beratnya $0,4-1 \mathrm{~kg}$, maka berat setiap keranjang yang bermuatan penuh bibit beratnya berkisar $60-85 \mathrm{~kg}$.

Pada uji coba menggunakan prototipe Semanggi-I, pengangkutan bibit ke lokasi tanam tidak dilakukan sebagaimana pada uji coba I yang mana bibit-bibit itu telah siap diangkut karena sudah berada dalam keranjang. Bibit yang akan dikirim pada uji coba ini berada di persemaian sejauh 30-70 meter dari titik pengangkutan. Bibit-bibit itu satu per satu dibongkar dan dipindah dari persemaian ke dalam keranjang bibit. Polibeg bibit semuanya berukuran 8 $\mathrm{cm}$, dengan tinggi bibit sangat bervariasi dari yang berukuran $20 \mathrm{~cm}$ sampai dengan hampir $100 \mathrm{~cm}$.

Karena kabel utama berada setinggi 30 meter di atas persemaian, maka bibit harus dipindah dari persemaian ke jalur utama. Keranjang tersebut kemudian diangkat dengan menggunakan teknik ikat dan ulur kabel yang terhubung dengan katrol yang menggantung pada kabel utama. Secara perlahan satu persatu keranjang bibit diangkat ke atas lereng untuk kemudian diturunkan dan satu persatu dipindah pada jalur kabel pengiriman. Setelah dikunci kuat pada kereta pembawa (carriage), keranjang bibit ditarik maju hingga setiap jarak tertentu (3-5 m) dengan cara kabel tanpa ujung (endless system), untuk kemudian dipasang lagi keranjang bibit yang lain hingga semua keranjang itu terpasang, barulah kemudian ke 11 keranjang ditarik hingga mencapai tujuan di seberang bukit. Bentangan kabel pada uji coba ini kurang lebih $320 \mathrm{~m}$ dan melewati lembah, bukit, sawah dan sungai kecil.

\section{B. Produktivitas Pengangkutan Bibit}

\section{Prototipe awal}

Pengangkutan bibit sistem kabel layang merupakan cara atau pilihan yang tepat pada kondisi lapangan sulit. Hasil uji coba awal pengangkutan bibit disajikan pada Tabel 1.

Dari Tabel 1 dapat dilihat hasil uji coba awal untuk mengangkut sebanyak 3-5 keranjang dengan isi antara 200-398 bibit per rit pengangkutan, memerlukan waktu antara 14,32-18,60 menit dengan rata-rata 16,35 menit untuk jarak 180 meter. Dengan demikian waktu yang diperlukan untuk pengangkutan satu rit keranjang yang telah siap bibit di dalamnya (bolak balik berikut penurunan bibit di tempat tujuan) rata-rata 3,63 menit. Pada uji coba berikutnya dilakukan beberapa perbaikan. Berdasarkan pengalaman tentang kelemahan dan kesulitan pelaksanaan setelah perbaikan itu terjadi peningkatan dengan rata-rata sebagaimana disajikan pada Tabel 2.

Dari Tabel 2 terlihat produktivitas kerja pengangkutan bibit naik menjadi 2,700 bibit.hm/jam pada uji coba lanjutan I dan hampir 2,900 bibit.hm/jam pada uji coba lanjutan II. Bila dibanding dengan penggunaan cara manual yang diperkirakan hanya dapat mengangkut 100 bibit.hm/jam per orang. Berarti untuk jumlah bibit yang sama akan memerlukan tenaga kerja 29 orang. Artinya penggunaan alat cukup efektif dan efisien. 
Tabel1. Uji coba prototipe mesin sistem kabel layang untuk angkutan bibit Table 1. Preliminary test of skyline system machine prototype for seedling hauling

\begin{tabular}{|c|c|c|c|c|c|c|}
\hline No & $\begin{array}{c}\text { Jumlah } \\
\text { keranjang } \\
\text { (Number of } \\
\text { boxes) } \\
\text { (buah/ } \\
\text { pieces) }\end{array}$ & $\begin{array}{l}\text { Jumlah bibit } \\
\text { (Number of } \\
\text { seedling) } \\
\text { (buah/ } \\
\text { pieces) }\end{array}$ & $\begin{array}{c}\text { Waktu *) } \\
(\text { Time) } \\
\text { (Menit/ } \\
\text { Minute) }\end{array}$ & $\begin{array}{c}\text { Jarak } \\
\text { (Dist.) } \\
\text { (m) }\end{array}$ & $\begin{array}{c}\text { Produktivitas } \\
\text { (Productivity) } \\
\text { (bibit.hm/jam) } \\
\text { (Seedling.hm/ hr }\end{array}$ & $\begin{array}{c}\text { Keterangan } \\
\text { (Remarks) }\end{array}$ \\
\hline 1 & 3 & 200 & 16,74 & 180 & $1.290,32$ & \multirow{5}{*}{$\begin{array}{l}\text { *) meliputi persiapan, } \\
\text { pengiriman, penu run- } \\
\text { an keranjang dan } \\
\text { bibit, pengembalian } \\
\text { dan penurunan keran - } \\
\text { jang/Covers the time for } \\
\text { preparation, sent, put off } \\
\text { boxes and seedlings, } \\
\text { returning and r eleasing of } \\
\text { boxes }\end{array}$} \\
\hline 2 & $\left.5^{* *}\right)$ & 348 & 18,60 & 180 & $2.020,65$ & \\
\hline 3 & $\left.5^{* * *}\right)$ & 398 & 14,32 & 180 & $3.001,68$ & \\
\hline 4 & 5 & 398 & 15,74 & 180 & $2.730,88$ & \\
\hline $\begin{array}{c}\text { Jumlah/ } \\
\text { Total }\end{array}$ & 18 & 1.344 & 65,4 & 720 & $9.043,52$ & \\
\hline $\mathrm{Rata}^{2} /$ Mean & 4,5 & 336 & 16,35 & 180 & $2.260,88$ & \\
\hline
\end{tabular}

Keterangan (Remarks) : **) Dua keranjang berisi polibeg berdiameter $20 \mathrm{~cm}$, 3 lainnya polibeg ukuran 10 $\mathrm{cm}$ (Two boxes containing plasticpolybags of $20 \mathrm{~cm}$ diameter, while three others of $10 \mathrm{~cm}$ diameter) ***) Satu keranjang berisi polibeg ukuran diameter $20 \mathrm{~cm}$, 4 lainnya berisi polibeg ukuran diameter $10 \mathrm{~cm}$ ( One box containing plastic polybags of 20- cm diameter, while three others of $10 \mathrm{~cm}$ diameter)

\section{Alat angkut model Semanggi - I}

Produktivitas kerja pengangkutan bibit dari lokasi persemaian ke jalur kabel pengiriman dengan menggunakan 9 keranjang disajikan pada Tabel 3.

Tabel 3 memperlihatkan pengumpulan bibit dari lokasi persemaian ke jalur kabel pengiriman bibit di lereng bukit, memerlukan waktu 1- 6 menit dengan rata-rata 3,70 menit. Sedangkan untuk pengisian bibit ke dalam 11 keranjang diperlukan waktu sekitar 30 menit. Cukup lamanya waktu pemrosesan ini disebabkan belum adanya pengalaman untuk menggunakan teknik pengereman manual. Dengan demikian pemindahan bibit dari persemaian ke jalur kabel pengiriman tercapai sebanyak 1.476 batang.hm/jam. Bila jarak persemaian lebih dekat lagi misal hanya $20 \mathrm{~m}$; maka prestasinya bisa meningkat hingga 4.400 batang per jam.

Selanjutnya ke sebelas keranjang dikirim ke seberang bukit sejauh 320 meter dengan memerlukan waktu 37,45 menit (dibulatkan 38 menit) untuk 1.476 batang atau rata-rata 3,45 menit per keranjang. Berarti waktu yang diperlukan seluruhnya adalah $(33,3+30+37,45)$ menit $= \pm 1$ jam 42 menit. Pada percobaan kedua, pengumpulan bibit ke dalam sebelas keranjang memerlukan waktu \pm 20 menit, 10 menit lebih cepat karena pekerja yang membantu mengisikan ke dalam keranjang ditambah 3 orang. Pengangkutan keranjang ke jalur kabel pengiriman seperti disajikan pada Tabel 4. 
Table 2. Uji coba lanjutan khusus untuk pengiriman bibit

Table 2. Further trial test for seedling hauling

\begin{tabular}{|c|c|c|c|c|c|c|c|c|c|}
\hline \multirow[b]{2}{*}{ No } & \multicolumn{5}{|c|}{ Uji coba lanjutan (Further trial I) } & \multicolumn{4}{|c|}{ Uji coba lanjutan II (Further trial II) } \\
\hline & $\begin{array}{c}\text { Jarak } \\
\text { (Distance) } \\
\text { (m) }\end{array}$ & $\begin{array}{c}\text { Jumlah } \\
\text { keranjang } \\
\text { Number of } \\
\text { boxes) } \\
(\text { buah } / p c)\end{array}$ & $\begin{array}{c}\text { Jumlah } \\
\text { bibit } \\
\text { (Number of } \\
\text { seedlings) } \\
\text { (buah/pc) }\end{array}$ & $\begin{array}{l}\text { Waktu } \\
\text { (menit) } \\
\text { (Time) } \\
\text { (minute) }\end{array}$ & $\begin{array}{c}\text { Produktivitas } \\
\text { bibit.hm/ } \\
\text { jam) } \\
\text { (Productivity) } \\
\text { (seedling.hm/ } \\
\text { hr) }\end{array}$ & $\begin{array}{l}\text { Jumlah } \\
\text { keranjang } \\
\text { (Number } \\
\text { of boxes) } \\
\text { (buah/pc) }\end{array}$ & $\begin{array}{c}\text { Jumlah } \\
\text { bibit } \\
\text { Number } \\
\text { of seedlings } \\
\text { (buah/pc) }\end{array}$ & $\begin{array}{c}\text { Waktu } \\
\text { (Time) } \\
\text { (menit/ } \\
\text { minute) }\end{array}$ & $\begin{array}{l}\text { Produktivitas } \\
\text { (bibit.hm/jam) } \\
\text { (Productivity) } \\
\text { (seedling.hm/hr) }\end{array}$ \\
\hline 1 & 180 & 6 & $479 *)$ & 19,02 & $2.719,87$ & 5 & $\left.388^{*}\right)$ & 16,6 & $2.524,34$ \\
\hline 2 & 180 & 5 & $\left.388^{*}\right)$ & 14,6 & $2.870,14$ & 4 & $297 *)$ & 11,24 & $2.853,74$ \\
\hline 3 & 180 & 4 & $297 *)$ & 11,48 & $2.794,08$ & 3 & $\left.206^{*}\right)$ & 7,98 & $2.787,97$ \\
\hline 4 & 180 & 3 & $\left.206^{*}\right)$ & 8,4 & $2.648,57$ & 2 & $\left.115^{*}\right)$ & 5,10 & $2.435,29$ \\
\hline 5 & 180 & 2 & $\left.115^{*}\right)$ & 5,64 & $2.202,13$ & 1 & 91 & 2,61 & $3.765,52$ \\
\hline 6 & 180 & 1 & 91 & 3,83 & $2.566,06$ & & & & \\
\hline 7 & 180 & 3 & $\left.206^{*}\right)$ & 8,64 & $2.575,00$ & & & & \\
\hline 8 & 180 & 3 & $\left.206^{*}\right)$ & 5,79 & $3.842,49$ & & & & \\
\hline \multicolumn{2}{|c|}{ Jumlah/Total } & 27 & 1988 & 77,4 & $22.218,33$ & 15 & 1097 & 43,53 & $14.366,86$ \\
\hline \multicolumn{2}{|c|}{$\mathrm{Rata}^{2} /$ Mean } & 3,38 & 248,50 & 9,68 & $2.777,29$ & 3 & 219,4 & 8,71 & $2.873,37$ \\
\hline
\end{tabular}

Keterangan (Remark) : *) 1 buah keranjang berisi ukuran polibeg diameter $20 \mathrm{~cm}$ sedang lainnya berisi polibeg ukuran diameter $10 \mathrm{~cm}$ (One box containing plastic polybags of 20-cm diameter, while three others of 10-cm diameter)

Dalam praktek pengiriman bibit pada sistem kabel layang itu dilakukan sekaligus pada 11 keranjang dengan jarak antar keranjang 4-5 meter. Dengan demikian dalam proses ini setelah keranjang yang satu sampai di tempat tujuan segera diangkat dan dibongkar isinya, dan segera pula dipindahkan ke jalur kabel balik. Setelah selesai, baru disusul dengan keranjang berikutnya hingga tuntas seluruhnya. Oleh karena itu terjadi proses seakan-akan tidak ada waktu bongkar. Waktu bongkar terjadi paralel bersamaan dengan waktu pengiriman untuk keranjang berikutnya. Lebih lamanya waktu kosong terjadi karena ada kegiatan bongkar bibit dan pemasangan kembali keranjang tersebut di jalur kabel. Kemungkinan lain dari lebih lama waktu yang diperlukan tersebut adalah karena untuk bongkar keranjang harus melepas pengencang yang kuncinya terpaksa harus dicari dulu karena jatuh atau perlu pengencangan dua kali karena pemasangan pertama kurang pas dan harus diulang.

Namun demikian, pengangkatan keranjang bibit untuk diangkut melalui kabel utama menjadi jauh lebih cepat, dengan memerlukan waktu rata-rata kurang dari satu menit untuk seluruh proses. Oleh karena itu produktivitasnya meningkat lebih dari tiga kali, yaitu dari 1.476 batang menjadi 4.506 batang.

Pada proses pengiriman keranjang itu lebih lanjut, hasil pencatatan memperlihatkan bahwa waktu yang diperlukan untuk semua kegiatan termasuk menurunkan bibit dari keranjang, bongkar keranjang setelah keranjang kosong itu balik adalah 45 menit. Dengan demikian semua proses kegiatan itu diperlukan waktu $\pm(10+45)$ menit atau 55 menit. Berarti 37 menit lebih cepat dibanding pada uji coba yang pertama. 
Tabe13. Pengangkatan bibit dari persemaian ke jalur kabel untuk pengangkutan Table 3. Lifting of seedlings from nursery bed to cable way for transportation

\begin{tabular}{|c|c|c|c|c|c|c|c|}
\hline \multirow{2}{*}{ No. } & \multicolumn{4}{|c|}{$\begin{array}{l}\text { Waktu transportasi (Transportation time) } \\
\text { (Menit/Minute) }\end{array}$} & \multirow{2}{*}{$\begin{array}{c}\text { Jarak } \\
\text { (Dist.) } \\
(\mathrm{m})\end{array}$} & \multirow{2}{*}{$\begin{array}{l}\text { Jumlah } \\
\text { bibit } \\
\text { (Number of } \\
\text { seedlings) } \\
\text { (Batang) } \\
\text { (Pieces) }\end{array}$} & \multirow{2}{*}{$\begin{array}{l}\text { Produktivitas } \\
\text { (Productivities) } \\
\text { (Bt.hm/jam) } \\
(\text { Pcs.hm/hour) }\end{array}$} \\
\hline & $\begin{array}{l}\text { Persiapan } \\
\text { (Preparation) }\end{array}$ & $\begin{array}{c}\text { bibit } \\
\text { (Seedling } \\
\text { tranportation) }\end{array}$ & $\begin{array}{c}\text { Kembali *) } \\
\text { (Return) }\end{array}$ & $\begin{array}{l}\text { Jumlah } \\
\text { (Total) }\end{array}$ & & & \\
\hline 1 & 0.40 & 0.53 & 2.78 & 3.72 & 60 & 135 & 1,308 \\
\hline 2 & 0.37 & 0.52 & 3.50 & 4.38 & 50 & 135 & 924 \\
\hline 3 & 0.37 & 0.95 & 3.95 & 5.27 & 50 & 135 & 768 \\
\hline 4 & 0.73 & 0.47 & 2.83 & 4.03 & 50 & 135 & 1,004 \\
\hline 5 & 0.55 & 0.58 & 2.13 & 3.27 & 50 & 135 & 1,240 \\
\hline 6 & 0.50 & 0.55 & 2.20 & 3.25 & 50 & 135 & 1,246 \\
\hline 7 & 0.37 & 0.57 & 0.90 & 1.83 & 50 & 135 & 2,209 \\
\hline 8 & 0.30 & 0.67 & 0.85 & 1.82 & 50 & 135 & 2,229 \\
\hline 9 & 0.38 & 1.55 & 3.80 & 5.73 & 60 & 135 & 2,355 \\
\hline Total & 3.97 & 6.38 & 22.95 & 33.30 & 470 & 1215 & 13,283 \\
\hline $\begin{array}{l}\text { Rata }^{2} \\
\text { (Mean) }\end{array}$ & 0.44 & 0.71 & 2.55 & 3.70 & 52.2 & 135.0 & 1,476 \\
\hline
\end{tabular}

Keterangan (Remarks): Digunakan dengan dua jalur kabel, satu untuk mengirim bibit dan kabel lainnya untuk pengiriman kembali keranjang kosong (Using two cables, one cable for sending seedlings and another one for returning empty boxes)

*) Berikut kegiatan memindahkan keranjang bibit pada jarak 3-5 meter (Including replacement of seedling boxes at the distance of 3-5 meters)

Berdasarkan uji coba ini, dapat dihitung bahwa bila jarak pengangkutan bibit hanya 100 meter, maka produktivitas alat untuk pengangkutanya saja adalah $1476^{*}(60 / 45) *(320 / 100)=$ 6.297 batang/jam. Jumlah ini masih sebatas keranjang yang ada, yang apabila keranjang bibit itu lebih banyak, misal 16 keranjang, maka jumlah bibit yang dapat diangkut akan jauh lebih banyak.

Dari uraian di atas dapat dilihat bahwa waktu yang diperlukan untuk memproses pengiriman bibit mulai dari pemasukan bibit ke dalam keranjang, pengangkatan keranjang, pengiriman keranjang, bongkar bibit, dan pengembalian keranjang serta bongkar keranjang adalah sekitar 5 menit. Suatu proses yang cukup cepat dan efektif. 
Tabel 4. Pengangkatan bibit dari persemaian ke jalur pengiriman bibit lanjutan Table 4. Lifting-up seedlings from nursery bed to skyline cable site

\begin{tabular}{|c|c|c|c|c|c|c|c|}
\hline \multirow[b]{2}{*}{ No. } & \multicolumn{4}{|c|}{$\begin{array}{l}\text { Waktu pengangkutan (Transportation time) } \\
\text { (Menit/Minute) }\end{array}$} & \multirow{2}{*}{$\begin{array}{c}\text { Jarak } \\
(\text { Dist. }) \\
(\mathrm{m})\end{array}$} & \multirow{2}{*}{$\begin{array}{c}\text { Jumlah bibit } \\
\text { (Number of } \\
\text { seedlings) }\end{array}$} & \multirow{2}{*}{$\begin{array}{l}\text { Produktivitas } \\
\text { (Productivities) } \\
\text { (Bibit.hm/jam) } \\
\text { (Seedlings.hm/hr) } \\
\text { (buah.hm/jam) } \\
\text { Pengiriman/ } \\
\text { Sending operation }\end{array}$} \\
\hline & $\begin{array}{c}\text { Persiapan } \\
\text { (Preparation) }\end{array}$ & $\begin{array}{l}\text { Muatan } \\
\text { (Loaded) }\end{array}$ & $\begin{array}{c}\text { Kosong } *) \\
(\text { Empty) }\end{array}$ & $\begin{array}{l}\text { Jumlah } \\
\text { (Total) }\end{array}$ & & & \\
\hline 1 & 0.08 & 0.11 & 0.31 & 0.49 & 50 & 135 & 8,262 \\
\hline 2 & 0.11 & 0.14 & 0.24 & 0.48 & 50 & 135 & 8,397 \\
\hline 3 & 0.15 & 0.19 & 0.19 & 0.53 & 50 & 135 & 7,608 \\
\hline 4 & 0.19 & 0.24 & 0.24 & 0.67 & 50 & 135 & 6,043 \\
\hline 5 & 0.24 & 0.28 & 0.29 & 0.81 & 50 & 135 & 5,031 \\
\hline 6 & 0.29 & 0.32 & 0.33 & 0.94 & 50 & 135 & 4,287 \\
\hline 7 & 0.33 & 0.37 & 0.37 & 1.08 & 50 & 135 & 3,748 \\
\hline 8 & 0.39 & 0.43 & 0.44 & 1.26 & 50 & 135 & 3,215 \\
\hline 9 & 0.44 & 0.47 & 0.48 & 1.40 & 50 & 135 & 2,903 \\
\hline 10 & 0.48 & 0.51 & 0.51 & 1.50 & 50 & 135 & 2,708 \\
\hline 11 & 0.12 & 0.26 & 0.35 & 0.73 & 50 & 135 & 5,547 \\
\hline Total & 2.82 & 3.32 & 3.7 & 9.89 & 550 & 1485 & 410 \\
\hline $\begin{array}{r}\operatorname{Rata}^{2} / \\
\text { Mean }\end{array}$ & 0.26 & 0.30 & 0.34 & 0.90 & 50 & 135 & 4,506 \\
\hline
\end{tabular}

\section{Analisa Biaya}

Salah satu dari komponen biaya ialah penggunaan bahan bakar yang dalam hal ini berupa solar. Harga solar di lokasi setempat sebesar Rp 5.000,- per liter. Adapun kapasitas tangki dari mesin diesel merk Changchai ini berukuran $20 \mathrm{~cm}$ x $20 \mathrm{~cm}$ x $15 \mathrm{~cm}$ atau sebanyak 6 liter. Dari pengalaman selama melakukan percobaan diketahui bahwa pemakaian solar selama kegiatan uji coba ialah sebanyak 6,55 x 0,4 x 1 lt $=2,62$ lt untuk selama waktu 6 jam. Berarti solar yang digunakan sekitar 0,44 lt/jam. Pemakaian bahan bakar itu jelas cukup irit, yang bila diuangkan setara dengan Rp 2.500 untuk setiap operasi pengangkutan bibit selama waktu satu jam.

Untuk membangun prototipe awal alat angkut bibit, dengan menggunakan mesin motor $70 \mathrm{cc}$ berikut kelengkapannya diperlukan biaya sebesar Rp 20 juta, sedangkan untuk alat angkut bibit model Semanggi-I, biaya yang diperlukan adalah sebesar Rp 40 juta terdiri 
atas konstruksi mesin sebesar Rp 25 juta, kabel utama dua gulung masing-masing 350 meter, kabel tanpa ujung (endless cable) 750 meter, dua buah tirfor, kabel baja berikut katrol-katrol dan sakel serta klem seluruhnya bernilai Rp 15 juta.

Dengan investasi sebesar itu dan berdasarkan analisis biaya untuk prototipe awal diperoleh biaya tetap dan biaya pengoperasian sebesar Rp 38.535/jam. Dengan produktivitas angkutan bibit 2.870 batang/jam maka biaya angkut bibit per batang adalah sebesar Rp 13,42 (dibulatkan menjadi Rp 14/batang). Untuk prototipe Semanggi-I, hasil analisis biaya pemilikan dan pengoperasian alat diperoleh sebesar Rp 42.695/ jam. Berarti biaya pengiriman bibit per batang dengan produktivitas kerja 6.500 batang/jam adalah sebesar Rp 6,57 (dibulatkan menjadi Rp 7/batang). Rincian analisis biaya kedua prototip disajikan pada Tabel 5.

Memperhatikan besaran rupiah untuk pengiriman bibit yang demikian cukup murah sementara kualitasnya juga lebih baik dibanding cara manual yang risikonya lebih besar; maka rekayasa alat angkut sistem kabel layang cukup memberikan harapan besar bagi percepatan kegiatan rehabilitasi lahan.

Di samping itu penanganan bibit yang sembarangan/kasar, menyebabkan peningkatan kegiatan metabolisme yang akan mempercepat penurunan cadangan karbohidrat. Gangguan teknis terhadap bibit atau penanganan yang tidak hati-hati ini akan mengurangi potensi tumbuh akar, depresi pertumbuhan mikoriza dan merangsang tekanan air (Von der Gonna, 1990).

Oleh karena itu upaya rehabilitasi hutan yang umumnya berada pada kondisi lapangan yang berat, penggunaan alat Semanggi-I dengan menggunakan sistem kabel layang dan media angkut untuk pengiriman bibit model keranjang diharapkan dapat menjadi solusi yang dapat diandalkan. Di samping biayanya relatif murah, risiko untuk penurunan kualitas bibit dapat diatasi.

\section{KESIMPULAN DAN SARAN}

Berdasarkan uraian di atas maka dapat ditarik kesimpulan dan saran sebagai berikut

1. Model alat untuk pengiriman bibit dapat dibangun dengan menggunakan tenaga penggerak mesin motor maupun diesel. Namun dilihat dari berbagai hal baik teknis maupun ekonomis, maka pilihan penggunaan mesin diesel lebih disarankan dibanding penggunaan mesin sepeda motor.

2. Hasil rekayasa alat pengangkutan bibit pada medan sulit yang diberi nama model "Semanggi-I" memperlihatkan prestasi kerja cukup baik.

3. Sekalipun drum lifting pada Semanggi-I belum diuji cobakan, namun penggunaan satu drum endless saja terbukti cukup efektif untuk mengangkut bibit dari bawah lembah ke jalur kabel di atas bukit dengan menggunakan kombinasi katrol dan kabel. Teknik ini merupakan hal yang baru, yang juga dapat dipakai untuk penarikan material lainnya seperti kayu atau batu.

4. Poduktivitas kerja pengiriman bibit dengan alat Semanggi-I adalah 6.500 bibit.hm/jam. 
Tabel 5. Analisis biaya penggunaan sistem kabel layang untuk pengiriman bibit Table 5. Cost analysis of skyline system for seedlings transportation

\begin{tabular}{|c|c|c|c|c|c|}
\hline \multirow[t]{2}{*}{ No } & \multirow[t]{2}{*}{ Uraian (Item) } & \multicolumn{2}{|c|}{$\begin{array}{c}\text { Investasi (Investment) } \\
\mathrm{x}(\mathrm{R} p 1000)\end{array}$} & \multicolumn{2}{|c|}{$\begin{array}{c}\text { Biaya pemilikan dan } \\
\text { pengoperasian } \\
(\mathrm{Rp} / \mathrm{jam}) / \\
\text { (Owning and operation cost) } \\
(\mathrm{R} p / \mathrm{hr})\end{array}$} \\
\hline & & $\begin{array}{c}\text { Prototipe } \\
\text { awal } \\
\text { (Initial } \\
\text { prototype) }\end{array}$ & $\begin{array}{l}\text { Semanggi } \\
- \text { I }\end{array}$ & $\begin{array}{c}\text { Prototipe } \\
\text { awal } \\
\text { (Initial } \\
\text { prototype) }\end{array}$ & $\begin{array}{l}\text { Semanggi } \\
- \text { I }\end{array}$ \\
\hline 1 & Harga alat (Price) & Rp 20.000 & Rp 40.000 & & \\
\hline 2 & Penyusutan (Depreciation cost) & & & 1.800 & 3.600 \\
\hline 3 & Asuransi (Insurance cost) & & & 360 & 720 \\
\hline 4 & Bunga (Interest rate) & & & 2.160 & 4.320 \\
\hline 5 & Pajak (Tax) & & & 240 & 480 \\
\hline 6 & Bahan bakar (Fuel) & & & $\left.5.000^{*}\right)$ & 2.500 \\
\hline 7 & Oli \& pelumas (Grease \& oil cost) & & & 100 & 200 \\
\hline 8 & Biaya pemeliharaan (Manitenance cost) & & & 2.000 & 4.000 \\
\hline 9 & Biaya operator (Operator cost) & & & 9.375 & 9.375 \\
\hline 10 & Biaya tenaga kerja (Helper cost) & & & 17.500 & 17.500 \\
\hline & Total & & & 38.535 & 42.695 \\
\hline
\end{tabular}

Keterangan (Remarks) : *) Harga bahan bakar setempat Rp 5.000,- per liter (Localprice of fuel Rp 5,000/ ltr)

5. Dengan perhitungan biaya investasi alat termasuk dengan kebutuhan kabel, katrol, tirfor untuk pengencang kabel, sakel serta klem dan kelengkapan lainnya seharga Rp 20 juta untuk prototipe pertama dan Rp 40 juta/unit untuk prototipe model Semanggi-I; maka dapat dihitung biaya tetap dan biaya pengoperasian masing-masing sebesar Rp 38.535/ jam dan Rp 42.695/jam. Dengan produktivitas kerja sekitar 2.800 batang.hm/jam pada prototipe pertama dan 6.500 batang.hm/jam untuk model Semanggi-I, maka biaya total pengiriman bibit masing-masing adalah sebesar Rp 13,4/bibit.hm dan Rp 6,57/bibit.hm.

6. Prototipe semanggi I masih perlu penyempurnaan lebih lanjut khususnya pada tongkat pemindah gigi dengan besi bulat yang lebih besar agar mesin lebih aman dan stabil. 
JURNAL Penelitian Hasil Hutan Vol. 25 No. 1, Februari 2007: 1-14

\section{DAFTAR PUSTAKA}

Anonim. 1974. Logging and log transport in tropical high forest. FAO Forestry Development Paper. No. 18. FAO. Rome.

Djapilus, A. 1988. Bibit akar telanjang pangkasan akar dan prospeknya dalam pembangunan Hutan Tanaman Industri. Duta Rimba Hal. 3-17 No 119-120/XVI. Perhutani. Jakarta.

Harahap, H. 1989. Volume produksi HTI lima kali produksi hutan alam. Sambutan tertulis pidato Menteri kehutanan pada pembukaan Seminar mahasiswa Kehutanan se Indonesia tanggal 12 Oktober 1988 di Yogyakarta. Kehutanan Indonesia No 32. Departemen Kehutanan. Jakarta.

Joyoadikusumo, S. 2004. Tanaman GN-RHL 2003 tumbuh baik di Jawa Timur. Majalah Kehutanan Indonesia. Edisi II 2004. Hal 2-4. Departemen Kehutanan. Jakarta.

Von der Gonna, M.A. 1990. Evaluation of an insulated canopy fo seedling transportation. Forest Engineering Research Institute of Canada. FRDA Report No 123. Vancouver, BC.Canada. 